\title{
Una mirada al principio de legalidad: A partir de la constitucionalización del derecho penal ecuatoriano
}

\section{A look at the principle of legality: From the constitutionalization of Ecuadorian criminal law}

\section{Uma olhada no princípio da legalidade: Da constitucionalização do direito penal equatoriano}

\author{
Lenin T. Arroyo-Baltán I \\ arroblente@hotmail.com \\ José J. Albert- Márquez II \\ albertmarquez@hotmail.com \\ Laura C. Joza-Mejía III \\ laurajozam@hotmail.com
}

\author{
Beatriz N. Muentes-Holguín IV \\ beatrizmuentes@gmail.com \\ Carmen M. Delgado-Alcívar V \\ carmendelgadoalcivar@hotmail.com \\ Ángela R. Aldaz-Quiroz V I \\ angelaldaz@hotmail.com
}

Recibido: 20 de febrero de 2018 * Corregido: 10 de abril de $2018 *$ Aceptado: 18 de junio de 2018

I. Doctor en Jurisprudencia, Magister en Ciencias Penales y Criminológicas, Abogado de los Tribunales y Juzgados de la República del Ecuador, Licenciado en Ciencias Sociales y Políticas, Docente de la Universidad Laica Eloy Alfaro de Manabí, Manta, Ecuador.

II. P.h.D., Secretario Académico la Facultad de Derecho y CC. EE. y Empresariales Responsable de Calidad de la Universidad de Córdoba. [UCO] España, Profesor de Filosofía, Universidad Laica Eloy Alfaro de Manabí, Manta, Ecuador.

III. Magister en Derecho Civil y Procesal Civil, Doctora en Jurisprudencia Ciencias Sociales y Políticas, Especialista Superior en Derecho Procesal, Especialista en Derecho Civil Comparado, Abogada de los Juzgados y Tribunales de la República, Docente de la Universidad Laica Eloy Alfaro de Manabí, Manta, Ecuador.

IV. Magister en Derecho Internacional Privado, Diploma Superior en Investigación del Derecho Civil, Especialista en Derecho Civil Comparado, Magister en Derecho Civil y Procesal Civil, Abogada de los Juzgados y Tribunales de la República, Licenciada en Ciencias Sociales y Políticas, Docente de la Universidad Laica Eloy Alfaro de Manabí, Manta, Ecuador.

v. Magister en Derecho Notarial y Registral, Abogada de los Juzgados y Tribunales de la República, Licenciada en Ciencias de la Educación Especialidad Comercio y Administración, Profesora de Segunda Enseñanza en la Especialidad de Comercio y Administración, Docente de la Facultad de Derecho de la Universidad Laica Eloy Alfaro de Manabí, Manta, Ecuador.

VI. Magister en Derecho Civil y Procesal Civil, Especialista en Derecho Comparado, Especialista en Diseño Curricular por Competencia, Abogada de los Juzgados y Tribunales de la República, Docente de la Universidad Laica Eloy Alfaro de Manabí, Manta, Ecuador. 


\section{Resumen}

En este artículo se analiza el carácter estrictamente legalista que podría tener la aplicación del principio de legalidad -como piedra angular- en el ordenamiento jurídico ecuatoriano, y se fundamenta una posición crítica sobre el debido proceso penal, a partir de la constitucionalización del derecho penal como un conjunto de garantías que pone límites al poder punitivo estatal. El mismo, metodológicamente, se llevó a cabo bajo un enfoque cualitativo. El corpus de la investigación estuvo constituido por la revisión bibliográfica y documental de los estamentos legales que refieren el principio de legalidad a partir de la constitucionalización del derecho penal ecuatoriano. Para el análisis de la información se utilizó el método de la hermenéutica y cuyos resultados permitieron, entre sus conclusiones explicar que desde una mirada al principio de legalidad, y a partir de la constitucionalización del derecho penal ecuatoriano, se pueden observar cuáles son las funciones de garantías criminal, penal, jurisdiccional y de ejecución de dicho principio, independientemente del cumplimiento de su otra doble función esencial de garantía, tanto en el aspecto político como jurídico, lo que significa que se trata de la piedra angular en donde reposa todo el ordenamiento jurídico estatal analizado.

Palabras clave: derecho penal; principio de legalidad; debido proceso penal; garantías.

\section{Abstract}

This article analyzes the strictly legalistic nature that might have the application of the principle of legality - as stone lens-in the Ecuadorian legal system, and is based a critical position on the due criminal process, from of the constitutionalization of criminal law as a set of guarantees that places limits on the State's punitive power. It is methodologically, carried out under a qualitative approach. The corpus of the research was formed by the literature review and documentary of the legal bodies which concerned the principle of legality from the constitutionalization of the Ecuadorian criminal law. Method of hermeneutics was used for the analysis of the information and results allowed, among their findings explain that from a look at the principle of legality, and from the constitutionalization of the Ecuadorian criminal law, they can be see what are the functions of criminal, criminal, judicial guarantees and implementation of this principle, independientemente of compliance with their other double warranty, both in political terms as legal, essential function which means that is $\mathrm{He}$ is the angular stone where all the analyzed State legal system rests. 
Una mirada al principio de legalidad: A partir de la constitucionalización del derecho penal ecuatoriano

Key words: criminal law; principle of legality; due process of law; guarantees.

\section{Resumo}

Este artigo descreve o caráter estritamente legalista que pode ter o princípio da legalidade, como a pedra angular no sistema legal equatoriana é analisado, e uma posição crítica sobre o devido processo penal baseia-se, a partir da constitucionalização do direito penal um conjunto de garantias que estabelece limites para o poder punitivo estatal. O mesmo, metodologicamente, foi realizado sob uma abordagem qualitativa. O corpus da investigação foi constituído pela revisão bibliográfica e documental das propriedades jurídicas que remetem ao princípio da legalidade a partir da constitucionalização do direito penal equatoriano. Para obter informações método de análise da hermenêutica que foram utilizados e cujos resultados levaram, entre seus achados explicam que a partir de um olhar sobre o Estado de direito, e da constitucionalização do direito penal equatoriana, você pode ver o que as funções de Garantias são penal, penal, jurisdicional e de execução deste princípio, independentemente do cumprimento de sua outra dupla função essencial de garantia, tanto nos aspectos políticos e legais, o que significa que é a pedra fundamental sobre a qual se baseia todo o sistema legal estadual. Analisados.

Palavras chave: direito penal; princípio da legalidade; processo penal devido; garantias.

\section{Introducción}

Los llamados límites de la potestad punitiva estatal son los factores relevantes para reducir o minimizar simbólicamente el poder del Estado de su acostumbrada y declarada vocación intervencionista. Esto supone que se tenga en cuenta, que la intervención penal es siempre una acción traumática, dolorosa y restrictiva con altos costos sociales. Por ello, durante mucho tiempo preocupó legitimar la intervención del derecho penal y al mismo tiempo someterla a los límites efectivos. Como puede observarse, que el único titular del abuso de poder para castigar es el Estado, y hay que someterlo al ordenamiento jurídico: (nullum crimen, sine lege). También, hay que someter a los jueces y tribunales que aplican las leyes y las penas: (nulla poena, sine legale iuditio). Así pues, no sólo a estos, incluso a límites tanto formales como materiales o límites político-criminales. 
Una mirada al principio de legalidad: A partir de la constitucionalización del derecho penal ecuatoriano

Es necesario analizar el modo en que cada uno de los límites del poder punitivo estatal para castigar, están plenamente establecidos por los principios de limitación del derecho penal, que en última instancia son las directrices que la doctrina impone como barreras a la construcción del derecho penal, por lo que, no hay nada más allá del poder a menos que afecte los derechos constitucionales. La discusión planteada sobre el principio de legalidad es referirnos a la Constitución de la República del Ecuador de 2008, y por el área que nos ocupa, a la norma penal, procesal, penitenciaria, y con plena fundamentación en el bloque de constitucionalidad como amparo de aplicación y protección de los derechos fundamentales.

Para poder describir el objetivo de este trabajo que se presenta es imprescindible en primer lugar definir ¿qué entendemos por principio? y ¿qué entendemos por legalidad?, para de esta manera poder conocer por qué el principio de legalidad es la piedra angular en donde descansa todo el ordenamiento jurídico del Estado ecuatoriano y, en consecuencia, entender la trascendental importancia que tiene en la efectiva aplicación del derecho penal en un Estado constitucional de derechos y justicia como el nuestro. A partir de lo expuesto, en este artículo se analiza el carácter estrictamente legalista que podría tener la aplicación del principio de legalidad -como piedra angular- en el ordenamiento jurídico ecuatoriano.

\section{Desarrollo}

Principio de legalidad: definición y elementos que lo integran

\section{Definición de principio}

El diccionario de la lengua española, expone diversas definiciones de principio. Una de ellas sostiene que es la "norma o idea fundamental que rige el pensamiento o la conducta". Es decir, de donde se parte, o el punto de partida de algo.

Como bien se sabe, en derecho, el principio tiene una acepción que es posible concretar. Alexy (2003) sostiene que: 
Una mirada al principio de legalidad: A partir de la constitucionalización del derecho penal ecuatoriano

De acuerdo con la definición estándar de la teoría de los principios, los principios son normas que ordenan que algo se realice en la mayor medida posible, de acuerdo con las posibilidades fácticas y jurídicas. Como consecuencia, los principios son mandatos de optimización, que se caracterizan por el hecho de que pueden ser cumplidos en diferentes grados y de que la medida ordenada en que debe cumplirse, no solo depende de las posibilidades fácticas, sino de las posibilidades jurídicas. (p. 95)

La importancia de los principios no radica tanto en la prescripción -nos referimos al ser incluidos en el derecho positivo como un imperativo- que generalmente encontramos en las primeras disposiciones de un tratado, constitución, ley, código, etc., sino en la posibilidad fáctica y jurídica de su realización, de su observancia.

\section{Definición de legalidad}

Según la definición que trae el diccionario $\mathrm{ABC}$, se puede establecer que, cuando se habla de legalidad se hace referencia a la presencia de un sistema de leyes que debe ser cumplido y que otorga la aprobación a determinadas acciones, actos o circunstancias, y como contrapartida desaprueba a otras tantas que afectan las normas establecidas y vigentes. La legalidad es, entonces, todo lo que se realice dentro del marco de la ley escrita y que tenga como consecuencia supuesta el respeto por las pautas de vida y coexistencia de una sociedad dependiendo de lo que cada una de ellas entienda por tal concepto.

El diccionario de la lengua española, define al principio de legalidad como un "principio jurídico en virtud del cual los ciudadanos y todos los poderes públicos está sometidos a las leyes y al derecho" (p.44).

Lo expuesto en las definiciones, ha de entenderse el principio de legalidad como el fundamento jurídico-político en virtud del cual los ciudadanos, así como todos los poderes públicos están sometidos al ordenamiento jurídico estatal.

\section{Elementos que integran el principio de legalidad}

Atendiendo al tenor literal de la legalidad, se puede estudiar desde el punto de vista formal y en su significado material. 
Una mirada al principio de legalidad: A partir de la constitucionalización del derecho penal ecuatoriano

La legalidad en sentido formal. La legalidad en el sentido formal expresa, en primer término, la reserva absoluta y sustancial de ley, es decir, en materia penal solo se puede regular mediante una ley los delitos y las penas, no se pueden dejar a otras disposiciones normativas esta regulación, ni por la costumbre, ni por el poder ejecutivo ni por el poder judicial pueden crearse normas penales tan solo por el poder legislativo y por medio de leyes que han de ser en los casos en que se desarrollen derechos fundamentales y libertades públicas.

La legalidad en sentido material. La legalidad en sentido material manifiesta una serie de requerimientos, que son: la taxatividad de la ley, es decir, las leyes han de ser precisas, éste requerimiento admite per se cuatro derivaciones, a saber:

El primero es, la prohibición de la retroactividad de las leyes penales, como regla general las normas penales son irretroactivas, excepto cuando éstas sean más favorables para el reo;

El segundo, constituye la prohibición de que la Función Ejecutiva dicte normas penales;

El tercero, trata la prohibición de la analogía en materia penal (generar razonamientos y conductas basándose en la existencia de semejanza con otra situación parecida); y,

El cuarto, es la reserva legal, manifestación que exige que los delitos y sus penas sean creados por ley y solo puedan ser creados por esta, descartándose otros medios de formación de legislación penal (como podrían ser la costumbre o las resoluciones judiciales).

\section{Una mirada al principio de legalidad}

\section{Contexto histórico}

Es justo reconocer que, en el ordenamiento jurídico penal, el principio de legalidad -para unos, de reserva para otros y de "estricta legalidad" para Ferrajoli (2009)- se concreta en la suprema garantía individual del hombre y la mujer, al no poderse atribuir delito a persona alguna, si éste no está previsto en la ley, consecuentemente, tampoco, podría existir pena o sanción, ni imputación en ningún proceso penal. En definitiva, para Ferrajoli (2009): 
Una mirada al principio de legalidad: A partir de la constitucionalización del derecho penal ecuatoriano

El principio de mera legalidad se limita en realidad a exigir que el ejercicio de cualquier poder tenga por fuente la ley como condición formal de legitimidad; el principio de estricta legalidad exige por el contrario a la propia ley que condicione a determinados contenidos sustanciales la legitimidad del ejercicio de cualquier poder instituido. (p. 857)

Este principio sin ninguna duda es la base de sustentación de la doctrina penal, cuyo progreso histórico rige desde las concepciones hechas en el "documento puente" suscrito por el rey Juan sin Tierra a favor de los nobles de Inglaterra en 1215. Posteriormente en 1237 aparece por primera vez en la Magna Charta Libertatum (Carta Magna de las Libertades), y en el art.39 se estable: "ningún hombre libre será tomado o aprisionado, o despojado o destruido de cualquier manera, ni pasaremos sobre él ni enviaremos por él, salvo por el juicio legal de sus pares o por la ley del país”. Así pues, nuestra atención pone de relieve el juicio legal ante su juez natural y por la ley del Estado previamente establecida. Esto implica precisamente, el ejercicio de poner límites a la autoridad del soberano, pero obviamente, respecto de sus pares. Evidentemente, este principio desde luego, bajo la perspectiva de la no retroactividad de la ley penal es consagrado en la Constitución de Maryland de 1776 señala:

(...) que las leyes retrospectivas, castigando a los hechos cometidos antes de la existencia de tales leyes, y por ellos sólo declaran criminal, son opresivas, injustas, e incompatible con la libertad; por lo cual ninguna ley ex post facto debe hacerse. (Art. 15)

Después es ratificado en la Constitución de los Estados Unidos de América el 28 de abril de 1788, y progresivamente fue incorporándose a las demás legislaciones de casi todos los países del mundo, por el requerimiento uniforme de casi todos los instrumentos y declaraciones internacionales sobre derechos humanos. No se debe olvidar que, entre los instrumentos y declaraciones internacionales sobre derechos humanos, se destacan: Declaración Universal de los Derechos Humanos (1948); Pacto Internacional de Derechos Civiles y Políticos (1966) Convención Americana sobre Derechos Humanos o Pacto de San José (1969). Resolución No. 1984/50 de 25 de mayo de 1984, mediante la cual el Consejo Económico y Social de las Naciones Unidas, aprueba las salvaguardias para garantizar la protección de los derechos de los condenados a la pena de muerte; Convención Europea para la Protección de los Derechos Humanos y las Libertades Fundamentales (1950); y, Carta Africana sobre Derechos Humanos y de los Pueblos (1981). Este principio es recogido en la Declaración de los derechos del hombre y del ciudadano, adoptada por la Asamblea Nacional Francesa el 26 de agosto 
de 1789, en su art. 8 dispone: "la ley no debe imponer otras penas que aquéllas que son estricta y evidentemente necesarias; y nadie puede ser castigado sino en virtud de una ley promulgada con anterioridad a la ofensa y legalmente aplicada”.

Ciertamente el principio de legalidad es el principal límite impuesto por las exigencias de los derechos constitucionales para el ejercicio de la potestad punitiva del Estado e incluye una serie de garantías para los ciudadanos y ciudadanas.

Por lo tanto, la esencia del principio de legalidad en materia penal es que una persona no puede ser ni juzgada ni sancionada por una acción u omisión que no esté establecida previamente en la ley penal, lo que coincide en última instancia, con el llamado "principio de legalidad de los delitos y de las penas".

Es decir, la ley penal debe contener la descripción típica de la conducta delictiva, así como la sanción o pena, todo cuanto, debe ser declarado previamente.

El jurista alemán Feuerbach (1801) es quien expone el principio de legalidad bajo los aspectos formales y materiales del derecho penal, a través de su formulación latina: "nulla poena sine lege" (no hay pena sin ley), nulla poena sine crimene (no hay pena sin crimen), nullum crimen sine poena legalis" (a todo hecho criminal le corresponde una pena legal). Bajo dichas locuciones latinas se puede establecer el fundamento científico del principio de legalidad. Desde luego, este principio tiene sus antecedentes en la referida Magna Charta, en la Constitución de Maryland y en la Declaración de los derechos del hombre y del ciudadano.

En este sentido, von Feuerbach es quien irradia y descifra uno de los logros principales de la Revolución francesa. Lo más sobresaliente en este sentido es que en la actualidad se conoce que el principio de legalidad se derivó en un principio de la teoría ilustrada del contrato social y presuponía una organización política basada en la división e independencia de poderes, en la que la ley fuese competencia exclusiva de los representantes del pueblo.

Frente a la corriente de la teoría ilustrada del contrato social Beccaria (1978), trasladó más que nadie el espíritu de la Ilustración al derecho penal, principalmente, al momento de sostener que: "sólo las leyes pueden decretar las penas de los delitos y esta autoridad debe residir en el legislador, que 
Una mirada al principio de legalidad: A partir de la constitucionalización del derecho penal ecuatoriano

representa toda la sociedad unida por el contrato social”. (p. 61). Lo cual podría ser la razón fundamental en que algunos autores atribuyen a Beccaria haber mentalizado o institucionalizado al principio de legalidad como la piedra angular del ordenamiento jurídico del Estado.

Es incuestionable que la mera existencia de una ley no garantiza el cumplimiento del principio de legalidad, pues, esto se desprende del hecho mismo de hacerse la idea de convivir en un Estado totalitario con sucesiva violación de los derechos individuales. Por lo tanto, para evitar este tipo de actos debe cumplirse una serie de requisitos tanto por el legislador como por el juzgador bajo las exigencias derivadas del principio de legalidad. En resumen, es necesario señalar -desde el punto de vista doctrinario- que los fundamentos de este principio es una garantía constitucional individual, propia de todo Estado constitucional de derechos y justicia. Es evidente que en este principio hay un valor histórico innegable, basado en el respeto a la persona humana -como se puede observar en el pensamiento jurídico de la Ilustración- pues, existe un valor científico que recibe luz y a su vez nos ilumina.

\section{Fundamento filosófico}

Si bien el asunto es cosas de filósofos, no debe ser desconocido por los penalistas, que el fundamento filosófico de este principio fue desarrollado por Carlos Cossio (1944) -el filósofo del derecho latinoamericano más destacado del siglo XX- quien partió del hecho de que existe una desigualdad entre el bien jurídico que se pretende proteger y la pena. Concluye que esa desigualdad entraña injusticia y, por lo tanto, es necesario restringir la imposición de la pena. Así pues, de esa manera se atenua la injusticia surgida de la desigualdad. Hubo autores - como el holandés Moddermann (1874), y el italiano Ferri (1933)-, que ridiculizaron la pretendida igualdad y correlación entre delito y castigo.

Es preciso señalar que Cossio (1944) puso de relieve la base filosófica de dichas restricciones que suponen el universal aforismo: nullum crimen, nulla poena sine lege. Pues, si dicha identidad entre el delito y sanción no existe, debe limitarse la pena cuanto más sea posible (Jiménez de Asúa, 1958). Desde luego, -dice Zavala (2002); siguiendo a Jiménez de Asúa (1958)- que: 
Una mirada al principio de legalidad: A partir de la constitucionalización del derecho penal ecuatoriano

Si no se estableciera sanción penal en fecha anterior del acto y si dejara al criterio de la justicia del juez la imposición de la pena en relación con la lesión causada se llegaría a desproporciones de tal naturaleza que no podría hablarse ni remotamente de una relación justa entre sanción y el bien jurídico lesionado. Por tal razón, pese a que los dos conceptos antes indicados son inmensurables, sin pretender que exista justicia entre los términos bien jurídico lesionado-pena, para impedir la arbitrariedad es necesario que tanto la pena como el delito se encuentran previamente descritos en la ley penal. (pp. 84-85)

No obstante, en Kant citado por Jiménez de Asúa (1958), se verifica la concepción filosófica más sobresaliente en su época, quien consideró a la justicia punitiva vinculada a la ley del talión: ojo por ojo, diente por diente, sangre por sangre. Es decir, la identidad campeaba en ella: al que mataba, se le daba muerte; al que lesionaba un bien protegido, se le infería igual daño.

\section{Fundamento científico}

El principio de legalidad fue elaborado por el jurista alemán von Feuerbach (1801), bajo la locución latina: nullum crimen, nulla poena sine praevia lege (ningún delito ni pena sin previa ley), de lo que se puede colegir también, los aforismos latinos: Nemo judex sine lege (ningún juez sin ley o nombramiento legal); Nemo damnetur sine legale judicium (nadie sea condenado sin juicio legal); y, nulla poena sine judicium (ninguna pena sin juicio legal).

En consecuencia, en necesario determinar - desde el punto de vista doctrinario- cuáles son los fundamentos de este principio, en cuanto es garantía constitucional individual, propia de un Estado constitucional de derechos y justicia.

Así, como en este principio hay un valor histórico innegable, basado en el respeto a la persona humana -como se puede observar en la época democrática liberal, inaugurada en el siglo de las luces-hay un valor científico que recibe luz y a su vez nos ilumina. Por ello, orientaremos el repetido tema del principio de legalidad, ejercitado desde la doctrina.

Jiménez de Asúa (1958) señala categóricamente que de la ley surge la pretensión punitiva estatal, para reprimir los actos catalogados en su texto como delitos, con la pena conminada, y por eso, la ley, es fuente y medida del derecho de penar. En consecuencia, el Estado no puede castigar una conducta que 
no esté previamente tipificada en la ley penal, ni menos imponer penas que no estén establecidas para el correspondiente delito, producto de la acción u omisión del agente.

Sin embargo, - como bien dice Maggiore (2000) - que de lo que no se puede dudar es que este principio por su universalidad representa una gloriosa conquista de la conciencia jurídica, que obedece la exigencia de absoluta justicia. Pues, invalidarlo o disminuirlo, revelaría una irrefutable regresión histórica de la humanidad y de la comunidad científica.

Ciertamente, en un Estado de derecho debe proteger al individuo no sólo mediante el derecho penal, sino también del derecho penal (Roxin, 1997). De ello, se colige que el principio de legalidad, en el Estado constitucional de derechos y justicia debe excluir todo tipo de arbitrariedad del ejercicio de la potestad punitiva estatal, por el reconocimiento de los derechos son progresivos y para el humano y la naturaleza.

Justamente, el ilustre maestro Zavala (2002), reflexiona sobre el hecho de que "Ningún gobierno puede considerarse democrático si no reconoce y respeta el principio de legalidad" (p. 85). Por ello, resulta imposible excluir su fundamento político criminal, sin embargo, hacerlo, implicaría desconocer los derechos fundamentales de los coasociados de este principio, y afectaría a lo que Ferrajoli (2009) denomina "democracia sustancial" en un Estado constitucional de derechos y justicia.

\section{Requisitos cuadripartitos del principio de legalidad}

Los requisitos cuadripartitos atribuidos al principio de legalidad están enunciados como: Lex scripta: como el orden de escritura y los requisitos o reserva de la ley penal; Lex praevia: como el mandato de la no retroactividad de la ley penal; Lex certa: como el mandato de determinar taxatividad, como fundamento en la limitación impuesta a las normas penales a acudir a normas extrapenales; y, Lex stricta: como la prohibición de la analogía por parte de los jueces y juezas y, en general, el requisito de estricta observancia del principio de legalidad en la aplicación de la ley penal, que se desarrolla a continuación:

\section{Lex scripta o de los delitos y las penas}

Es el derecho penal exclusivamente positivo (Ley penal escrita), es decir, excluye tanto la costumbre y los principios generales del derecho para establecer los delitos y las penas, estableciendo la reserva 
Una mirada al principio de legalidad: A partir de la constitucionalización del derecho penal ecuatoriano

al poder legislativo del Estado. En el caso ecuatoriano, esta reserva corresponde a la Asamblea Nacional, es decir, sólo la función legislativa es la que puede de manera obligatoria "tipificar infracciones y establecer las sanciones correspondientes". (art. 132 num 2 de la Constitución, 2008)

Ahora bien, la ley sea escrita y represente, por una parte, el rechazo a la costumbre dentro del derecho penal; por otra, que la fuente generadora de hechos punibles esté sometida al proceso de formación de la ley dentro de un Estado constitucional de derechos y justicia y, en especial que sea la expresión de la voluntad popular. (Bustos, 2008)

Es evidente que el principio de legalidad, como principio básico del debido proceso se manifiesta en la legislación positiva ecuatoriana como una verdadera función de garantía del individuo, a través de la reserva de la ley.

\section{La Constitución (2008) establece:}

Nadie podrá ser juzgado ni sancionado por un acto u omisión que, al momento de cometerse, no esté tipificado en la ley como infracción penal, administrativa o de otra naturaleza; ni se le aplicará una sanción no prevista por la Constitución o la ley. Sólo se podrá juzgar a una persona ante un juez o autoridad competente y con observancia del trámite propio de cada procedimiento. (art. 76 num. 3)

Ello no quiere decir, entonces, que otras fuentes de derecho no tengan aplicación en el sistema de justicia penal, como, por ejemplo, la propia costumbre, la jurisprudencia o los principios generales del derecho. Por el contrario, ellas pueden tener un papel importante en las llamadas normas penales en blanco, es decir, aquellas que, según Binding (1916), remiten para la descripción del hecho a una norma jurídica de inferior categoría, un reglamento administrativo, por ejemplo, nivel en el cual las fuentes del derecho son más amplias que el derecho penal. (Bustos, 2008)

Así pues, se consagra en nuestra Constitución, el principio de legalidad. Por ello, podemos decir enfáticamente, que este principio ha sido incorporado al ordenamiento jurídico ecuatoriano como una garantía individual, producto de la exigencia de las convenciones y tratados internacionales sobre derechos humanos. Lo que sí es necesario dejar en claro es que, el principio de legalidad de acuerdo con la Constitución, lleva implícita tres partes que muy bien pueden ser desintegradas como sigue: 
Una mirada al principio de legalidad: A partir de la constitucionalización del derecho penal ecuatoriano

El primer general o sustancial, implica que: "nadie podrá ser juzgado ni sancionado por un acto u omisión que, al momento de cometerse, no esté tipificado en la ley como infracción penal, administrativa o de otra naturaleza". Pues bien, este precepto constitucional establece que el hecho "cometido" es lo que debe estar previamente descrito como delito, es decir, que en ello radica la esencia misma del principio de legalidad. La segunda guarda relación con la imposición de la pena al establecer que: "ni se le aplicará una sanción no prevista por la Constitución o la ley”. La tercera parte, está relacionada con la garantía de juez natural para los justiciables, es decir, que: "sólo se podrá juzgar a una persona ante un juez o autoridad competente y con observancia del trámite propio de cada procedimiento". (Constitución, 2008, art. 76, num. 3)

Es importante destacar que la vigencia de este principio no está reservada única y exclusivamente para el debido proceso penal, sino que comprende a todos los procesos, sean éstos administrativos o de cualquier otra naturaleza, según reza la disposición constitucional antes citada. En realidad, el principio de legalidad se fundamenta, en la protección de cada ciudadano y ciudadana para que no sean víctimas de un proceso investigativo si no ha cometido una acción típica y antijurídica determinada previamente en la ley penal. En este sentido, también el Código Orgánico Integral Penal -en adelante COIP-, a más de contemplar las directrices generales del principio de legalidad expuestas en líneas anteriores, permite validar la existencia de los tipos extrapenales o mejor llamados normas penales en blanco al señalar "que no hay infracción penal, pena, ni proceso penal sin ley anterior al hecho. Este principio rige incluso cuando la ley penal se remita a otras normas o disposiciones legales para integrarlas" (art. 5 num. 1). No hay que olvidar que las denominadas leyes penales en blanco inciden a la vez en el mandato de reserva de ley en materia penal. Está claro que deben ser percibidas desde una perspectiva global y poner de manifiesto que, aun cumpliendo los requisitos formales, también las normas extrapenales deben ofrecer las mínimas condiciones para su determinación normativa en el contexto del sistema penal ecuatoriano. (Arroyo, 2005)

Por otra parte, en el COIP, art. 586, se establece que, en todos los delitos, en tanto que no se hubiere iniciado la instrucción fiscal, el fiscal podrá solicitar al juez o jueza de garantías penales el archivo de la investigación, cuando cumpla con las exigencias determinadas en dicho imperativo legal, mediante requerimiento debidamente fundamentado. Es evidente que dicho imperativo legal es consecuencia procesal del principio de legalidad, instituido en la Constitución y en la ley positiva, respectivamente. 
De manera que el principio de legalidad se manifiesta en diversas etapas de la actividad coercitiva del Estado.

Ante todo, como premisa previa, no se debe iniciar una "fase de investigación previa" si es que, objetivamente, no existe el delito, pues si la conducta sujeta a indagación no se adecua a un tipo penal concreto, el principio de legalidad impide tal indagación.

\section{Pues bien, el COIP dispone:}

La investigación previa no podrá superar los siguientes plazos, contados desde la fecha de su inicio: 1. En los delitos sancionados con pena privativa de libertad de hasta cinco años durará hasta un año. 2. En los delitos sancionados con pena privativa de libertad de más de cinco años durará hasta dos años. 3. En los casos de desaparición de personas, no se podrá concluir la investigación hasta que la persona aparezca o se cuente con los elementos necesarios para formular una imputación por el delito correspondiente, fecha desde la cual empezarán los plazos de prescripción. Si la o el fiscal considera que el acto no constituye delito o no cuenta con los elementos de convicción suficientes para formular cargos podrá dar por terminada la investigación incluso antes del cumplimiento de estos plazos, mediante el requerimiento de archivo. (art. 585)

De lo expuesto se llega a la conclusión que el principio de legalidad o reserva, cumple una doble y esencial función de garantía, tanto en el aspecto político como en el jurídico. Por ello, es considerado la piedra angular donde descansa el ordenamiento jurídico estatal.

\section{Lex praevia o mandato de la no retroactividad}

La ley debe ser previa a los hechos que se pretenden sancionar, debe haber sido promulgada con anterioridad a la comisión de los hechos, por ello la ley penal no es retroactiva y no se puede aplicar con anterioridad a su entrada en vigor. En otras palabras, como el mandato de la no retroactividad de la ley penal.

Como se ha mencionado en la propia definición del principio de legalidad, la conducta desviada y la pena correspondiente deben estar previstas en la ley antes de que ocurra el hecho delictivo o acto humano, es decir, que dentro de los límites que traza el principio de legalidad, nos encontramos con el principio de Lex praevia, de manera que el hecho denominado delito y su sanción se encuentre 
Una mirada al principio de legalidad: A partir de la constitucionalización del derecho penal ecuatoriano

legislado previamente, con lo cual se prohíbe de manera general la retroactividad de la ley penal. En efecto, lo que más interesa es el hecho de impedir que el legislador pretenda con ello resolver casos particulares, -como quien dice- convirtiéndose en juzgador, pues de esta manera se evita también la arbitrariedad.

Dicho de otra manera, una conducta solo puede ser considerada delito y atribuirle una pena si está prevista previamente como tal y con la correspondiente consecuencia jurídica en una ley positiva vigente en el momento en que se realiza la conducta en cuestión. Por lo tanto, el juez, la jueza o el tribunal de garantías penales deben juzgar los hechos con arreglo a la ley en vigor en el momento de su comisión u omisión. Este principio Lex praevia es recogido por la Constitución (2008, art. 76, num. 3), que comprende, tanto a la vigencia de la ley penal como a otras disposiciones sancionadoras que comprenden el ordenamiento jurídico del Estado. En la formulación de este mandato, la ley entrará en vigencia a partir de su promulgación en el Registro Oficial y por ende será obligatoria y se entenderá conocida de todos desde entonces. En realidad, se podrá en la misma ley, fijarse un plazo especial para su vigencia a partir de su promulgación. (Código civil, art. 6)

En efecto, "la derogación de las leyes podrá ser expresa o tácita. Es expresa cuando la nueva ley dice expresamente que deroga la antigua. Es tácita cuando la nueva ley contiene disposiciones que no pueden conciliarse con las de la ley anterior. La derogación de una ley puede ser total o parcial" (Código civil, art. 37). Además, se dispone que "la derogación tácita deja vigente en las leyes anteriores, aunque versen sobre la misma materia, todo aquello que no pugna con las disposiciones de la nueva ley" (Código civil, art. 38). Más, aún "la ley especial anterior no se deroga por la general posterior, si no se expresa". (Código civil, art. 39)

Como resultado de todo esto, surge el interrogante -para determinar dónde se producen diversos efectos de la ley penal en el tiempo- ¿cuál es la ley aplicable a un acto humano hecho o realizado bajo el efecto de una vieja ley ahora derogada, o cuando se estima en la validez de una ley diferente, la nueva ley? Frente al interrogante, tan apegado al principio de favorabilidad, nos parece que la respuesta a breves trazos y en buen romance, resulta ser que la ley penal rige para el futuro, es decir, debe ser previa a la comisión del hecho, y los hechos cometidos antes de la vigencia de la ley no pueden ser perseguidos por esta. 
Una mirada al principio de legalidad: A partir de la constitucionalización del derecho penal ecuatoriano

En un primer momento la cuestión parece estar muy clara por cuanto "toda infracción será juzgada y sancionada con arreglo a las leyes vigentes al momento de su comisión" (art. 16 núm. 1 del COIP) y la respuesta es que la ley penal no es retroactiva; en cambio, como excepción es retroactiva solamente cuando es más benigna para el justiciable. Así, pues, dicha respuesta se fundamenta, en el principio in dubio pro reo o favor rei, así como en el principio de favorabilidad, respectivamente, lo que significa el reconocimiento de la aplicación retroactiva de la ley penal más favorable en la Constitución (2008) al expresar que:

En caso de conflicto entre dos leyes de la misma materia que contemplen sanciones diferentes para un mismo hecho, se aplicará la menos rigurosa, aun cuando su promulgación sea posterior a la infracción. En caso de duda sobre una norma que contenga sanciones, se la aplicará en el sentido más favorable a la persona infractora. (art. 76, núm. 5)

En un segundo momento la favorabilidad se reconoce como un principio general en materia penal, y se lo delimita al momento de expresar que: "se aplicará la ley penal posterior más benigna sin necesidad de petición, de preferencia sobre la ley penal vigente al tiempo de ser cometida la infracción o dictarse sentencia" (art. 16 núm. 2 del COIP). Así, como también, por una parte, la "duda a favor del reo: la o el juzgador, para dictar sentencia condenatoria, debe tener el convencimiento de la culpabilidad penal de la persona procesada, más allá de toda duda razonable". Y por otra, la "favorabilidad: en caso de conflicto entre dos normas de la misma materia, que contemplen sanciones diferentes para un mismo hecho, se aplicará la menos rigurosa aun cuando su promulgación sea posterior a la infracción". (COIP, 2014, art. 5, numerales 3 y 2)

La aplicación de los principios antes mencionados requiere algunas consideraciones sobre cómo determina la ley más favorable al infractor o reo. Hay que tener en cuenta que, en algunos casos, para determinar que la ley penal es más favorable para el acusado debe tomarse en consideración la legislación extrapenal. Así sucede, por ejemplo, cuando se presenta el problema de la sucesión de leyes se plantea la solución dentro del contexto de las normas penales en blanco. Por consiguiente, para determinar cuál es la ley que más favorable al acusado, resulta absolutamente imprescindible resolver íntegramente el hecho con arreglo a las dos leyes en colisión, y a continuación, comparar las consecuencias jurídicas desfavorables para el justiciable que se derivan de la aplicación de una u otra forma. Desde luego, resuelto el supuesto de hecho de plena conformidad con la ley que estaba en vigor 
en el momento de su comisión u omisión y de acuerdo con la ley que entró en vigor después (efecto sobre el proceso penal) con la opción de la ley más favorable al acusado no debe tener mayores consecuencias para los juzgadores.

\section{Lex certa o mandato de determinación taxativa}

Bajo la rúbrica de garantía formal, se relaciona con el contenido material del principio de legalidad. Por su parte, la ley penal a pesar de su carácter generalizado, debe describir con precisión de una manera clara y comprensible, en definitiva, una clara determinación de las de conductas desviadas y las penas que ordenan como consecuencia de su realización.

Este requisito Lex certa, es denominado también principio de taxatividad o mandato de certeza. Así pues, para que se cumpla con dicha función, la ley deberá previamente establecer cuáles son las conductas desviadas que ameritan expiación. De manera que la vaguedad de las definiciones de los tipos penales constituye una disminución o atentado a la seguridad jurídica establecida como imperativo en el art. 82 de la Constitución.

Como queda establecido, la exigencia clara y coherente de las conductas desviadas en el denominado principio de taxatividad o mandato de certeza, está estrechamente relacionada con la faceta garantista de un Estado constitucional de derechos y justicia, en el sentido de que si los delitos y las penas están establecidas con claridad, el ciudadano y la ciudadana estarán protegidos constitucional y legalmente contra la posible arbitrariedad de un régimen político-administrativo-judicial totalitario, por cuanto no se puede implementar una norma general de disuasión o consecuencia jurídica cuyo presupuesto no puede ser conocido con certeza por el ciudadano o la ciudadana. De hecho, hay diferentes grados de taxatividad: en primer lugar, el legislador a veces puede dar vuelta a los conceptos que requieren logro judicial, pero cuyo significado genérico se desprende de la propia ley. Pero luego están las llamadas tipos o normas penales en blanco que establece el legislador en los que los límites de la delincuencia son difusos con el consiguiente detrimento de la seguridad jurídica. (Cfr. García-Pablos, 2005 y Muñoz, 2005) 
Una mirada al principio de legalidad: A partir de la constitucionalización del derecho penal ecuatoriano

También se relaciona con el principio jurídico y político de la legalidad, de manera que un conjunto de definiciones vagas e imprecisas hacen suponer dejar al libre albedrío de los jueces y juezas la decisión sobre qué actos humanos son delitos y cómo debe sancionarse, cuando esta decisión corresponde exclusivamente al poder legislativo. En resumen, de nada sirve exigir que las sanciones y las penas estén establecidas en una norma previamente determinada, si esta se ha formulado de manera imprecisa que ni el ciudadano ni la ciudadana saben lo que se declara punible por ley o qué consecuencia jurídica contiene, o si la norma sirve como límite efectivo a la potestad jurisdiccional y sancionadora del juez o la jueza para evitar sanciones arbitrarias.

Resulta un paso importante para evitar penas arbitrarias "los tipos penales han de redactarse con la mayor exactitud posible, evitando los conceptos elásticos, recoger las inequívocas consecuencias jurídicas y prever sólo marcos penales de alcance limitado" (Jescheck, 2014, p. 122). Es decir, que la ley debe contener de manera preferente los elementos descriptivos en la concreción de los tipos penales: precepto y consecuencia jurídica. Por ejemplo: "la persona que, por culpa mate a otra, será sancionada con pena privativa de libertad de tres a cinco años" (art. 145 del COIP); y, "la persona que lesione a otra será sancionada de acuerdo con las siguientes reglas: [...]". (art.152 del COIP). Al respecto, Zaffaroni, Alagia \& Slokar (2002) consideran que "es menester exigir al legislador que agote los recursos técnicos para otorgar la mayor precisión posible a los mandatos legales prohibitivos" ( $\mathrm{p}$. 116).

\section{Lex stricta o prohibición de la analogía}

Está prohibido a las juezas y jueces u operadores del sistema de justicia penal, en general, el requisito de estricta observancia del principio de legalidad en la aplicación de la ley penal. Es decir, que el principio nulla poena sine lege stricta, incide sobre la no aplicación de la analogía en el campo del derecho penal. Cabe señalar que la analogía no puede ser fuente ni de los delitos ni de las penas. Por ello, le está vedado el paso a los jueces y juezas a cualquier interpretación extensiva de la ley penal o interpretación análoga impide una adecuada subsunción en la calificación jurídica de los hechos.

Ahora bien, respeto a la analogía, se debe indicar que no procede en el derecho penal, por cuanto un acto humano constituye un hecho único y particular, a más que las normas penales por su propia naturaleza, son restrictivas de derechos, es decir, que nos encontramos frente al principio de 
Una mirada al principio de legalidad: A partir de la constitucionalización del derecho penal ecuatoriano

inaplicabilidad por analogía de la ley penal. Conforme a la exigencia de la Lex stricta, el principio de legalidad penal prohíbe el uso de la analogía. Este enunciado expresa que "queda prohibida la utilización de la analogía para crear infracciones penales, ampliar los límites de los presupuestos legales que permiten la aplicación de una sanción o medida cautelar o para establecer excepciones o restricciones de derechos" (art. 13, inc. 3 del COIP). Es decir, que según este principio se restringen derechos y garantías constitucionales.

Como se ve, se trata del requisito de la Lex stricta que impone una interpretación estricta de la ley penal, en la que se hace evidente un mandato dirigido exclusivamente a los operadores del sistema de justicia penal (jueces y juezas), según el cual las prohibiciones y las sanciones punitivas, sólo pueden ser aplicadas aquellas que están expresamente previstas y reguladas por la ley de manera estricta. Por lo tanto, en aplicación de la ley, es necesario para determinar qué hipótesis se recogen en ésta, sin excederse de los límites establecidos por la ley en la combinación de ciertos supuestos de hecho, ya que al superar este límite serían incompatibles con esta garantía.

El uso de la analogía en las resoluciones o sentencias penales, es una violación flagrante de la expresión del principio de legalidad, ya que la analogía no es realmente una forma de interpretación legal de la ley penal, sino de la aplicación de la misma. Puede decirse, que la diferencia entre la interpretación que no sólo permite, sino que también requiere, y la analogía está prohibido sólo si perjudica al justiciable o reo.

En otras palabras, la primera alternativa de interpretación es la búsqueda del sentido o significado del texto legal y posponerlo como principio jurídico, de ahí que, para ser considerada como tal, debe permanecer dentro de los límites de lo posible, es decir, en el "sentido literal" de la ley. En cambio, que la segunda va más allá de la interpretación de los límites permitidos, suponiendo la aplicación del derecho penal a los casos que no están cubiertos por cualquiera de los posibles significados de sus letras, pero análogo a otro comprendido en el texto de la ley.

Ahora bien, "la prohibición de la analogía in malam partem tiene su fundamento en que solo el legislador, por disposición constitucional, puede crear delitos y penas" (Jescheck y Weigend, 2014, p. 56). Por su parte, el profesor italiano Antolisei (1988); citando a Carrara, aclara mucho más el 
Una mirada al principio de legalidad: A partir de la constitucionalización del derecho penal ecuatoriano

panorama al referirse que "por analogía no puede extenderse la pena de un caso al otro; debe extenderse de un caso a otro la excusa por analogía”. (p. 79)

De allí que, la garantía de prohibición de la analogía sólo se aplica cuando es perjudicial para el acusado, reo o justiciable (analogía in malam partem), es decir, cuando surten los efectos de la esta jurisdicción sancionadora a los casos no previstos por ley penal, es por demás entendible.

En contraste, la analogía favorable (analogía in bonam partem) es aceptada por los procesos de interpretación de la ley penal (Cfr. García-Pablos, 2005 y Muñoz, 2005). De hecho, la tendencia de la aplicación de un beneficio para el acusado, cuando su situación es análoga a lo que motiva a este beneficio, parece lógico que sea asumida por la doctrina dominante.

\section{Función de garantía del principio de legalidad}

En base a las ideas fundamentales del principio de legalidad desarrolladas por Paul Johann Anselm von Feuerbach como parte del Código de Baviera de 1813, aunque el principio de legalidad del que deriva fue creado por Cesare Beccaria. En Ecuador, el fundamento del principio de legalidad está reglado en el num. 3, art. 76 de la Constitución de 2008. La evolución de la doctrina dominante ha dado paso a que este principio esté diseñado en cuatro garantías, a saber: criminal, penal, jurisdiccional y ejecución. Así pues, en nuestro sistema de justicia penal estas garantías se encuentran en los artículos 5.1, 53, 624 y 666 del COIP, las que brevemente se comentan a continuación.

\section{Función de garantía criminal}

Esta garantía exige que el delito esté previamente establecido en la ley. Por ello, "nadie podrá ser juzgado ni sancionado por un acto u omisión que, al momento de cometerse, no esté tipificado en la ley como infracción penal...”. (Constitución, 2008, art. 76, núm. 3)

Es incuestionable que cuando la Constitución establece "no podrá ser juzgado", no solo se refiere a la actividad de órgano jurisdiccional penal en la etapa de juicio, sino al hecho de que una persona no podrá siquiera ser sujeto de investigación policial o fiscal, si el acto u omisión no está previsto por la ley como delito. Así pues, el verdadero sentido del principio de legalidad consiste en la legitimación de la protección de todo ciudadano o ciudadana a no ser víctima de un proceso investigativo mientras 
Una mirada al principio de legalidad: A partir de la constitucionalización del derecho penal ecuatoriano

no hubiere cometido una acción u omisión que amerite reproche estatal. Por eso mismo, no basta con publicitar que no hay delito sin pena, lo importante es la existencia previa de la ley.

\section{Función de garantía penal}

Está claro que como en la garantía anterior se requiere que la ley establezca la pena que corresponde a cada delito en particular. Es decir, que en la hipótesis de que una persona realice un acto supuestamente contrario a la convivencia social, pero que no esté tipificado como delito, evidentemente no se podrá iniciar proceso penal alguno "ni se le aplicará una sanción no prevista por la Constitución y la ley”. (Constitución, 2008, art. 76, núm. 3)

\section{Función de garantía jurisdiccional}

Es conocida también como garantía judicial, exige que la existencia del delito y la imposición de una pena se determinen por medio de sentencia judicial y de acuerdo con el procedimiento establecido. Es decir, salta a la vista la presencia de un juez natural, por cuanto, "solo se podrá juzgar a una persona ante un juez o autoridad competente y con la observancia del trámite de cada procedimiento". (Constitución, 2008, art. 76, núm. 3)

Es evidente que "la pena se cumple una vez ejecutoriada la sentencia" (COIP, art. 624.1). En suma, la pena no se aplica hasta que la sentencia no esté ejecutoriada o sea firme, lo que significa que, hasta ese momento, el acusado no puede ser considerado responsable y se presume inocente. Pero si se encuentra en prisión, lo estará en situación preventiva y aún sin cumplir la pena. Esto significa que el requisito de sentencia definitiva para el cumplimiento de la pena se debe a la presunción de inocencia establecida en el núm. 2, art. 76 de la Constitución (2008)

\section{Función de garantía en la ejecución}

La esencia de esta garantía radica en la ejecución de las penas debidamente impuestas por juez o tribunal. La ejecución debe estar sujeta o sometida a la ley. Finalmente, "la ejecución de las penas y medidas cautelares corresponderá al Organismo Técnico encargado del Sistema de Rehabilitación Social, bajo el control y supervisión de las o los jueces de garantías penitenciarias" (COIP, art. 666 num.1). En otras palabras, el principio de legalidad exige que para asegurar el cumplimiento de las penas se debe realizar con total sumisión a las disposiciones de las normas de derecho positivo. Estas 
son las garantías que se encargan de velar por los ciudadanos y ciudadanas de posibles ataques venidos del poder judicial.

\section{Metodología}

Este trabajo se llevó a cabo bajo un enfoque cualitativo. El corpus de la investigación estuvo constituido por la revisión bibliográfica y documental de los estamentos legales que refieren el principio de legalidad a partir de la constitucionalización del derecho penal ecuatoriano. Para su análisis se utilizó el método de la hermenéutica, como herramienta de interpretación y explicación de los contenidos fundamentados en la Constitución de la Republica de Ecuador, el Código Civil y el Código Orgánico Integral Penal Ecuatoriano, permitiendo posteriormente presentar las conclusiones interpretativas del trabajo.

\section{Conclusiones}

A través de las locuciones latinas formuladas por von Feuerbach (1801): nulla poena sine lege (no hay pena sin ley), nulla poena sine crimene (no hay pena sin crimen), nullum crimen sine poena legalis" (a todo hecho criminal le corresponde una pena legal), se puede colegir cuál es el fundamento científico del principio de legalidad. Además, bajo estas mismas locuciones se intuye que se refieren a existencia de leyes que contengan el catálogo del delito y de las penas antes del cometimiento de los injustos penales.

A la sazón, de las ideas del ilustre profesor Zavala (2002), se debe entender que el principio de legalidad o principio de taxatividad penal, se manifiesta en diversas etapas de la actividad coercitiva del Estado. Ante todo, como premisa previa, no se debe iniciar una indagación previa si es que, objetivamente, no existe el delito, pues si la acción u omisión sujeta a la indagación no se adecua a un tipo penal concreto, el principio de legalidad impide el inicio de tal indagación.

La Constitución (2008) al establecer que "nadie podrá ser juzgado ni sancionado por un acto u omisión que, al momento de cometerse, no esté tipificado en la ley como infracción penal, administrativa o de otra naturaleza; ni se le aplicará una sanción no prevista por la Constitución o la ley” (art.76, núm. 3), significa que, en lo relativo a la pena, es el legislador o asambleísta, el llamado a examinar por vía ordinaria y abstracta la conducta delictiva relevante y la sanción que le corresponde. 
Una mirada al principio de legalidad: A partir de la constitucionalización del derecho penal ecuatoriano

Los instrumentos internacionales sobre derechos humanos: Declaración Universal de los Derechos Humanos (art. 11, núm. 2); Pacto de Derechos Civiles y Políticos (art. 15 núm. 1); Convención Americana sobre Derechos Humanos o Pacto de San José (art. 9); Convención Europea para la Protección de los Derechos Humanos y las Libertades Fundamentales (7 núm. 1); y, de la Carta Africana sobre Derechos Humanos y de los Pueblos (art. 7 núm. 2), coinciden en la construcción del principio de legalidad al señalar que a nadie se le "puede imponer pena más grave que la aplicable en el momento de la comisión del delito", esto significa que la pena tiene que estar determinada previamente en la ley. Así, se puede conocer con exactitud cuál es la pena más grave aplicable. Por ello, la Resolución No. 1984/50 de 25 de mayo de 1984, del Consejo Económico y Social de las Naciones Unidas, aprueba las salvaguardias para garantizar la protección de los derechos de los condenados a la pena de muerte.

En efecto, los requisitos cuadripartitos del principio de legalidad están explicados como: Lex scripta: el orden de escritura y los requisitos o reserva de la ley penal; Lex praevia: el mandato de la no retroactividad de la ley penal; Lex certa: el mandato de determinar taxatividad, como fundamento en la limitación impuesta a las normas penales a acudir a normas extrapenales; y, Lex stricta: la prohibición de la analogía por parte de los jueces y juezas y, en general, el requisito de estricta observancia del principio de legalidad en la aplicación de la ley penal. Esto implica, que la ley penal debe describir con claridad los elementos constitutivos de los tipos penales, en sentido contrario, se apostaría al riesgo del principio de legalidad, inherente a la labor legislativa en el ámbito normativo.

Finalmente, en una mirada al principio de legalidad, a partir de la constitucionalización del derecho penal ecuatoriano, se pueden observar cuáles son las funciones de garantías de dicho principio, a saber: función de garantía criminal; función de garantía penal; función de garantía función de garantía jurisdiccional; y, función de garantía en la ejecución. Independientemente, del cumplimiento de su otra doble función esencial de garantía, tanto el aspecto político como jurídico, lo que significa que se trata de la piedra angular en donde reposa todo el ordenamiento jurídico estatal como he dejado esbozado. 


\section{Referencias Bibliográficas}

Alexy, Robert (2003). Tres escritos sobre los derechos fundamentales y la teoría de los principios. Bogotá: Universidad Externado de Colombia, En serie Teoría Jurídica y Filosofía del Derecho No. 28.

Antolisei, Francesco (1988). En Manual de derecho penal. Parte general. ( $8^{\mathrm{a}}$. ed.). (trad. Juan del Rosal y Ángel Torio). Bogotá: Ed. Temis S.A.

Arroyo Baltán, Lenin T. (2002). En las garantías individuales y el rol de protección constitucional. Manta: Ediciones Arroyo.

Arroyo Baltán, Lenin T. (2005). En las normas penales en blanco y su legitimidad. Manta: Ediciones Arroyo.

Bonesana, Cesare, Marqués de Beccaria (1978). En de los delitos y de las penas. Buenos Aires: Ed. Heliasta S.R.L.

Bustos Ramírez, Juan (2008). En derecho penal. Parte general. (Obras escogidas) (1 ${ }^{\mathrm{a}}$ ed.). (Vol. 1). Quito: Ed. Jurídica del Ecuador.

Cossio, Carlos (1944). En la teoría egológica del derecho y el concepto jurídico de libertad. Buenos Aires: Ed. Losada S.A.

Diccionario ABC. Disponible en: https://www.definicionabc.com/derecho/legalidad.php. Consultado: 2017-08-05.

Ferrajoli, Luigi (2009). En derecho y razón. Teoría del garantismo penal ( $9^{a}$ ed.). Madrid: Ed. Trotta S.A.

Ferri, Enrico (1933). En principios del derecho penal. Madrid: Ed. Reus.

Feuerbach, Paul Johann Anselm von (1801). Lehrbuch des gemeinen in Deutschland geltenden peinlichen Rechts.

Jescheck, Hans-Heinrich \& Weigend, Thomas (2014). En tratado de derecho penal. Parte general (trad. Miguel Olmedo Cardenete) $5^{\text {a }}$ ed. corregida y ampliada (reimpresión). Granada: Ed. Colmares, S.L.

Jiménez de Asúa Luis (1958). En principios del derecho penal. La ley y el delito. Buenos Aires: Abeledo-Perrot. Editorial Sudamericana.

Maggiore, Giuseppe (2000). En derecho penal. Vol. 1. Bogotá: Ed. Temis S.A.

Modderman, A. E. (1874). La pena no es ningún mal. (Straf geen Kwaad). Amsterdam. 
Una mirada al principio de legalidad: A partir de la constitucionalización del derecho penal ecuatoriano

Muñoz Conde, Francisco (2005). En teoría general del delito. Bogotá: Editorial Temis S.A.

Organización de Estados Americanos (1969). En la Convención Americana sobre Derechos Humanos o Pacto de San José. Disponible en: http://www.tce.gob.ec/jml/bajar/ CONVENCION\%20AMERICANA\%20SOBRE\%20DERECHOS\%20HUMANOS.pdf.

Consultado: 2017-08-05.

Organización de las Naciones Unidas (1948). Declaración Universal de los Derechos Humanos. Disponible en: http://www.un.org/es/universal-declaration-human-rights/

Organización de las Naciones Unidas (1966). Pacto Internacional de Derechos Civiles y Políticos. Disponible en: http://www.ohchr.org/SP/ProfessionalInterest/Pages/CCPR. aspx. Consultado: 201708-05.

Organización de las Naciones Unidas (1984). Resolución No. 1984/50 de 25 de mayo de 1984, mediante la cual el Consejo Económico y Social de las Naciones Unidas, aprueba las salvaguardias para garantizar la protección de los derechos de los condenados a la pena de muerte. Disponible en: http:/www.ohchr.org/ SP/ProfessionalInterest/ Pages/ DeathPenalty.aspx. Consultado: 2017-08-05. Organización para la Unidad Africana (1981). Carta Africana sobre Derechos Humanos y de los Pueblos. Disponible en: http://www.acnur.org/t3/fileadmin/scripts/doc.php?file=t3/ fileadmin/Documentos/BDL/2002/1297. Consultado: 2017-08-05.

Real Academia Española (2014). Diccionario de la lengua española (23a ed.). Disponible en: http://dle.rae.es/?id=N40kRtA Consultado: 2017-08-05.

República del Ecuador (2005). Código Civil. (Codificación). Publicado en el Registro Oficial No.46, de 24 de junio de 2005. Disponible en: http://esilecdata.s3.amazonaws.com/ Comunidad/Leyes/CODIGO\%20CIVIL\%20(LIBRO\%20I) \%20Reformado\%20el\%2022-MAY2016.PDF. Consultado: 2017-08-05.

República del Ecuador (2008). Constitución de la República del Ecuador. Publicada en el Registro Oficial No.449, de 20 de octubre de 2008. Disponible en: http://www. inocar.mil.ec/web/images/lotaip/2015/literal_a/base_legal/A._Constitucion_republica_ecuador2008c onstitucion.pdf. Consultado: 2017-08-05.

República del Ecuador (2014). Código Orgánico Integral Penal. Publicado en el Registro Oficial Suplemento No. 180, de 10 de febrero de 2014. Disponible en: http://esilecdata. s3.amazonaws.com/Comunidad/Leyes/CODIGO\%20ORGANICO\%20INTEGRAL\%20PENAL, \%20COIP\%20Reformado\%20el\%2004-JUL-2017.PDF. Consultado: 2017-08-05. 
Roxin, Claus (1997). En derecho penal. Parte general. (9 ed. Vol. 1) (trad. Diego-Manuel Luzón Peña, Miguel Díaz \&García Conlledo \& Javier de Vicente Ramesal). Madrid: Ed. Civitas S.A.

Tribunal Europeo de Derechos Humanos (1950). Convención Europea para la Protección de los Derechos Humanos y las Libertades Fundamentales. Disponible en: http://www. echr.coe.int/Documents/Convention_SPA.pdf. Consultado: 2017-08-05.

Zaffaroni, Eugenio Raúl, Alagia, Alejandro \& Slokar, Alejandro (2002). En derecho penal. Parte general ( $2^{\mathrm{a}}$ ed.). Buenos Aires: Ed. Ediar.

Zavala Baquerizo, Jorge (2002). En el debido proceso penal. Guayaquil: Ed. Edino. 